\title{
Spiny Dogfish (Squalus Acanthias): Changes in Structural and Mechanical Properties Under Storage
}

\author{
Olena Sydorenko ${ }^{1}$, Nadiya Bolila ${ }^{1,}$, Ninel Forostyana ${ }^{2}$ \\ ${ }^{1}$ Department of Commodity Science, Safety and Quality Management, Faculty of Trade and Marketing, Kyiv National University of Trade and \\ Economics, Kyiv, Ukraine \\ ${ }^{2}$ Department of Engineering and Technical Disciplines, Faculty of Restaurant, Hotel and Tourism Business, Kyiv National University of Trade \\ and Economics, Kyiv, Ukraine
}

Email address:

L_fish@ukr.com (O. Sydorenko), nadiabolila@gmail.com (N. Bolila), forostyann@gmail.com (N. Forostyana)

${ }^{*}$ Corresponding author

\section{To cite this article:}

Olena Sydorenko, Nadiya Bolila, Ninel Forostyana. Spiny Dogfish (Squalus Acanthias): Changes in Structural and Mechanical Properties Under Storage. International Journal of Food Science and Biotechnology. Vol. 6, No. 1, 2021, pp. 1-7. doi: 10.11648/j.ijfsb.20210601.11

Received: December 17, 2020; Accepted: December 24, 2020; Published: January 22, 2021

\begin{abstract}
Fresh histological sections of the Black Sea spiny dogfish have been examined using a 500xSDM electron microscope. Experimental histological sections of the Black Sea spiny dogfish have been made along and across muscle fibers. Sections of skin and adipose tissue between the skin and the muscle have also been examined. PH value in the spiny dogfish muscle layers has been measured using a Kelilong Electron $\mathrm{pH}-150 \mathrm{MI}$ device. Thus, there are three zones determined: the first one is within 24-42 hours of storage with a $\mathrm{pH}$ ranging from 6,77; the second one - 46-78 hours with a $\mathrm{pH}$ in the range of 6,55; the third one - from 85 to 97 hours of storage with a pH of 6,41. The study of the elastic properties of fish is a study of the deformation properties. Regularities of change of rheological properties of fish depending on term and temperature mode of storage have been established. Graphs of values of deforming force of samples of different shelf life have been obtained, comparison of deformation time and size of deforming values have been made. Results of physical properties are placed in the process of optimizing the parameters of shelf life of the spiny dogfish. Mathematical models describing changes in the basic physicochemical properties of spiny dogfish in different storage parameters are.
\end{abstract}

Keywords: Spiny Dogfish, Microstructure, Deformation, Elasticity Coefficient, Structural and Mechanical Properties, The Shelf Life

\section{Introduction}

According to FAO, consumption of fish itself and fish products has grown up to $20,5 \mathrm{~kg}$ per capita over the past year. The FAO report "State of World Fisheries and Aquaculture" noted the high growth of fishing and consumption in the world, the constant development of aquaculture and effective fisheries management. By 2030, the world's total catch is predicted to grow up to 204 million tons. In 2018, catch amounted almost 179 million tons. It has been studied that fish consumption is one-sixth, and in some countries even half, of the total consumption of animal proteins by the population [1].

The urgent task is the effective use of domestic stocks of aquatic organisms, development of aquaculture and mariculture to obtain products of the predicted level of quality.
A promising raw material for the food industry may be the Black Sea spiny dogfish [2-4].

Freshness is one of the most important criteria for assessing the quality of fish. Currently, one searches effective and rapid methods for monitoring changes in fish quality depending on processing methods and shelf life [5-8].

Study of fish texture is the main feature used to assess the quality of freshness.

During the storage, there are changes in the protein composition of fish, which affects its rheological, structural-mechanical and functional properties [9].

Physical properties that play an important role in determining the quality of products include density, structural and mechanical, optical, thermophysical, sorption properties.

Plastic properties of raw materials characterize such rheological properties as elasticity coefficient, location 
parameter, Young's modulus, factor of safety. In the complex, they characterize structural and mechanical properties, which are an indicator of the quality of raw materials, determined by instrumental methods. The factor of safety characterizes the load limit at which the sample retains its integrity.

Instrumental methods for measuring structural and mechanical properties are the most common, and they are based on the use of various devices allowing to determine the rheological characteristics of the product, energy parameters of deformation, destruction of its structure, etc. [10-12].

Instrumental research methods have been performed using UMM (universal measuring machine), with the use of force sensors of various types [13-15].

\section{Materials and Methods}

\subsection{Material Procurement}

The Black Sea spiny dogfish has been comprehensively studied using modified instrumental research methods using UMM (Figure 1).

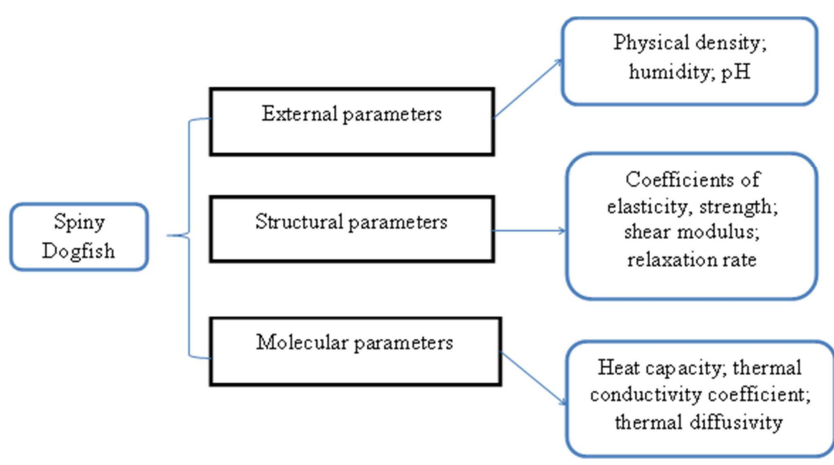

Figure 1. Directions of the spiny dogfish comprehensive study.

Experimental histological sections of the Black Sea spiny dogfish have been made along and across muscle fibers. Sections of skin and adipose tissue between the skin and the muscle have also been examined.

Sample 1 - a fresh spiny dogfish meat, sample 2 - chilled spiny dogfish meat, sample 3 - spiny dogfish meat of a long-term low temperature storage. Experimental samples have been taken from different parts of the shark carcass (near the head, middle and tail parts). Test specimens have been prepared to have the shape of a regular rectangle with linear dimensions: $49 \pm 0,5 \times 24 \pm 0,5(\mathrm{~mm})$. Samples were fixed vertically in the clamps of UMM and deformed up to $30 \%$, compared to the initial size [3, 4]. Deformation curves obtained have been processed using Excel and Advanced Grapher.

Structural and mechanical properties characterize the behavior of the product under the forced conditions and allow to relate force, deformation or its rate during the application of forces. They are not "pure" constants of the material and significantly depend on the shape and size of the body, load speed, surface condition, environmental influences, temperature, and structure.

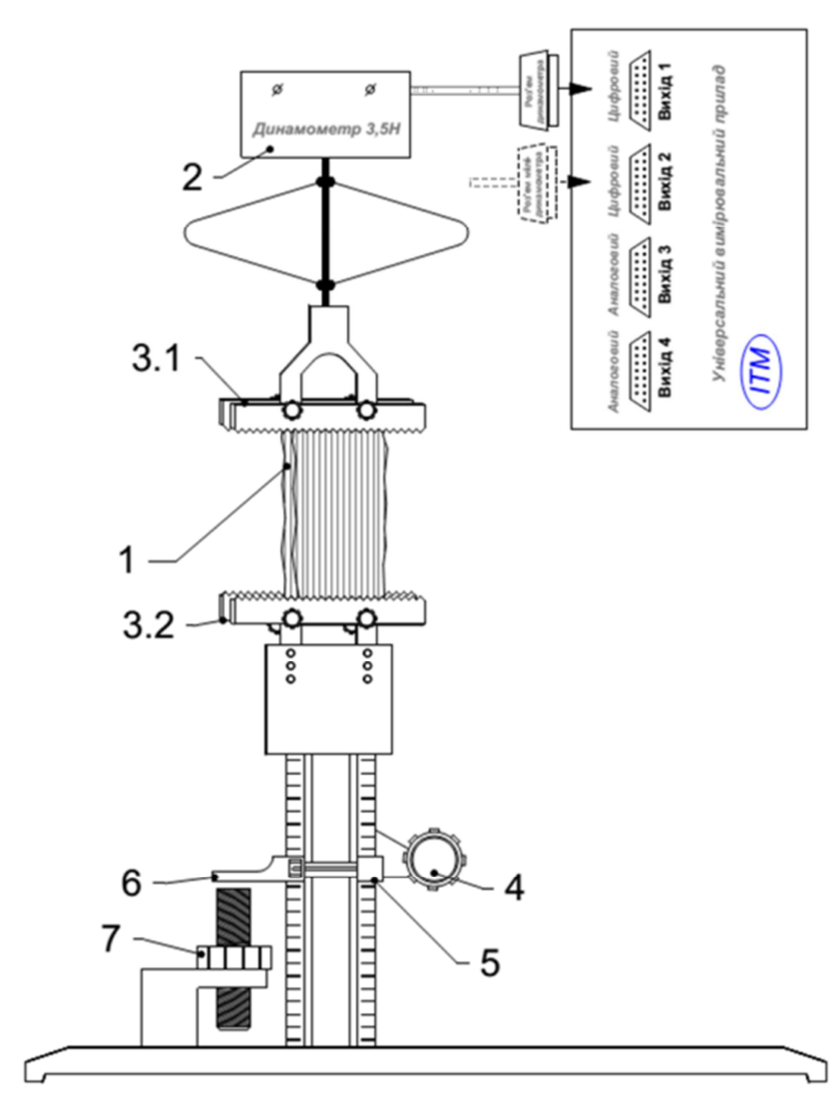

Figure 2. Scheme of the instrument for the study of structural and mechanical properties of meat (1-sample, 2- digital dynamometer ITMI, 3.1 - upper fixed clamp, 3.2 - lower movable clamp, handle for raising (lowering) the lower clamp, 5-tripod ruler, 6 - height limiter, 7 - height limiter screw, 8 - measuring cell).

\subsection{Microstructure of Muscle Fibers}

Structure of fish at the macro level was thoroughly studied by photographic methods. This method was performed using Micro-Measure software. Photos have been taken with a 500x SDM electron microscope using purple and red filters. The 500x SDM microscope matrix allows taking images with a resolution from 320x240 up to $1600 \times 1200$ pixels. Using the "Paralel" and "Distance Measurement" instruments, a distance between the structural formations of the object under study have been measured.

Resolution of the obtained photos is from 360 up to 1200 pixels. This is enough to get clear photos and size within $0.0001 \mathrm{~mm}$.

\section{3. pH Metry}

$\mathrm{PH}$ value in the spiny dogfish muscle layers has been measured using a Kelilong Electron pH-150MI device: one has made an incision and inserted into the muscle an electrode.

\subsection{Rheological Properties}

Most rheological properties are based on the establishment of patterns between the freshness of the product and its deformation properties. Linear and volume deformations of the samples have been investigated. Volume deformation is 
the compression of samples, and the establishment of the dependence of relaxation properties on the term and conditions of spiny dogfish storage. Axial deformation is the rupture of the cut plates under the action of the deforming force, and the establishment of the dependence of the coefficients of elasticity on the term and storage conditions.

During the experiment, sensors of the measuring device recorded the change of resultant force during deformation in real time, which was displayed on the computer display.

\subsection{Elastic Properties}

Structural and mechanical properties of fish reveal under the influence of normal or tangential stresses. These properties determine the behavior of histological sections of spiny dogfish meat in a tense state. Under the action of the applied force, the body of a fish is deformed. Mechanical behavior of the sample reflects the relationship between the deformation of the muscle structure and the tension in it.

Elasticity is the ability of bodies to quickly restore their previous shape or volume after the removal of deforming forces. An indicator that characterizes the ability of a material to exert elastic resistance to deformation is the modulus of elasticity, the coefficient of strength.

\section{Results and Discussion}

\subsection{Determination of the Microstructure of the Black Sea Spiny Dogfish Muscles}

Examination of the fish by photographic method allowed to clearly see the intermuscular structure of the fish and determine its thickness depending on the cut (Figure 3). The muscle fibers are spindle-shaped, with a sarcoplasm in the middle. The surface of muscle fibers is covered with an outer membrane - sarcolemma. Between the fibers, one can see layers of connective tissue - septa.

Composition of muscles and the structure of fish is determined by their way of life and chemical composition. Studying the structure of fish meat is important to explain the processes that take place during the cooling, freezing, drying, smoking, etc.

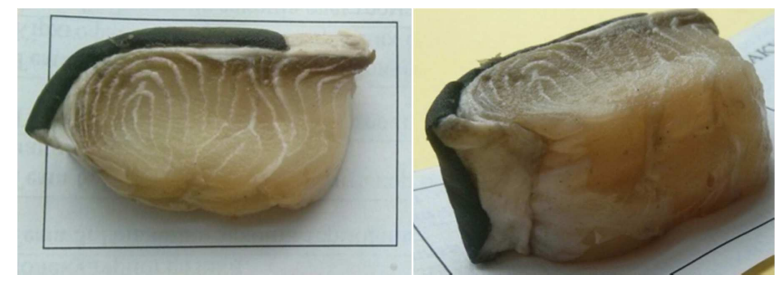

Figure 3. Photo of the Black Sea spiny dogfish sections.

Thickness of the muscle fibers in the cross section of shark is $0,0827-0,1004 \mathrm{~mm}$ (Figure 4). Distance between the fibers is from $0,1232 \mathrm{~mm}$ to $1556 \mathrm{~mm}$. Distance between the fibers along the fiber - from $0,0827 \mathrm{~mm}$ to $0,1573 \mathrm{~mm}$.

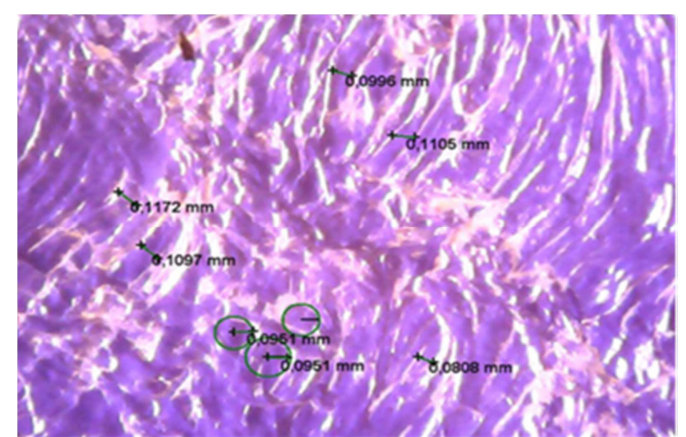

a) along the fibers

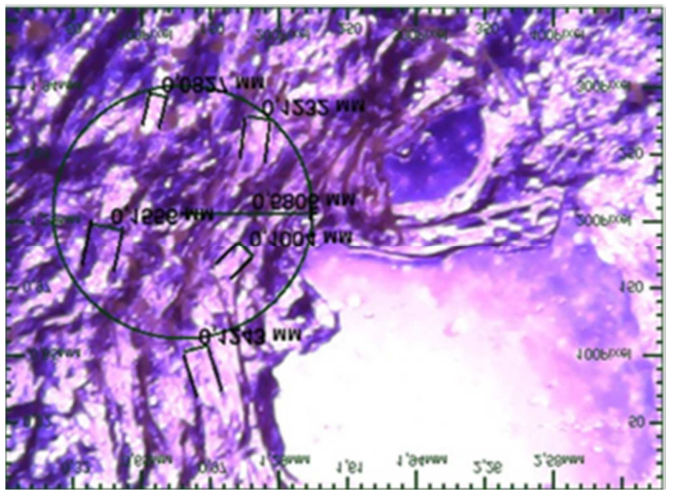

b) across the fibers

Figure 4. Photomicrograph of histological sections of the spiny dogfish.

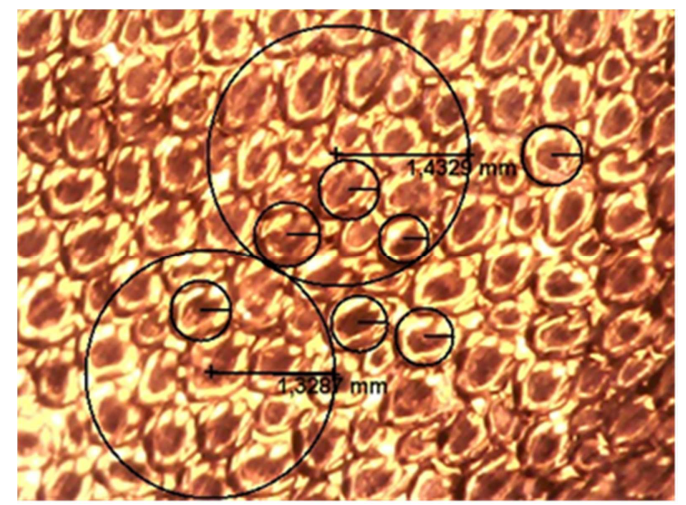

a) spiny dogfish scales

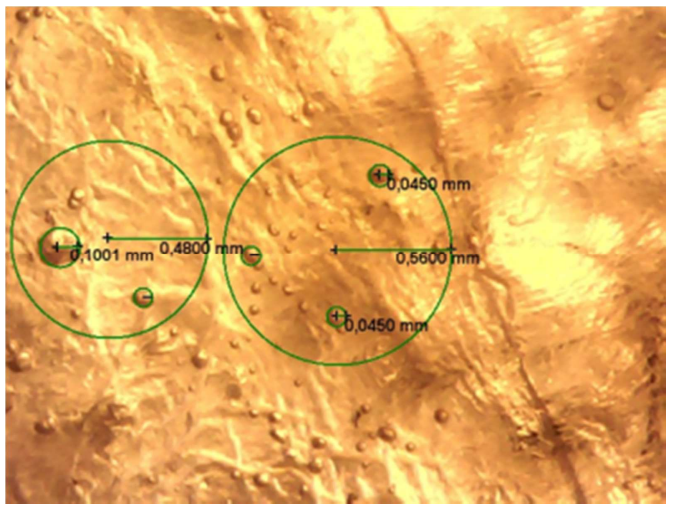

b) spiny dogfish subcutaneous fat capsules

Figure 5. Photomicrograph of the structure of the skin (a), subcutaneous layer (b). 
Analysis of photomicrographs of spiny dogfish fat capsules showed that the diameter of these capsules ranged from 0,09 $\mathrm{mm}$ up to $0,19 \mathrm{~mm}$ (Figure 5). The number of capsules in a certain area of $0,7088 \mathrm{~mm}^{2}$ was approximately 20 capsules.

Diameter of the spiny dogfish scales ranges from 0,53373 $\mathrm{mm}$ to $0,7164 \mathrm{~mm}$.

\subsection{Determination of Structural and Mechanical Properties of the Black Sea Spiny Dogfish}

General structural and mechanical properties of spiny dogfish are described by the following physical properties: physical density, $\mathrm{pH}$, coefficient of elasticity, location parameter. All of them are variable and depend on the time and temperature of storage of spiny dogfish. Therefore, they are functionally dependent quantities. By establishing a relationship between them, we can most likely determine the freshness of a spiny dogfish meat by one of the parameters.

At the initial stage, a change in $\mathrm{pH}$ with the shelf life and its change with storage conditions has been established.

Significant increase in $\mathrm{pH}$ in 18 hours of storage was observed; then gradual leveling, and increasing again in 84 hours. (Figure 5).

The $\mathrm{pH}$ value of fish varies widely from 3,6 up to 6,8 , which is explained by the influence of the environment, pre-death condition of the fish, presence of damage, accumulation of protein breakdown products, degree of autolysis. PH is usually lower for freshwater fish, and higher for marine fishes.

Figure 6 clearly shows the overlap of the areas corresponding to the optimal $\mathrm{pH}$ value for the spiny dogfish. Thus, there are three zones determined: the first one is within 24-42 hours of storage with a $\mathrm{pH}$ ranging from 6,77 ; the second one - 46-78 hours with a $\mathrm{pH}$ in the range of 6,55; the third one - from 85 to 97 hours of storage with a $\mathrm{pH}$ of 6,41 . Studies show that with increasing storage time, $\mathrm{pH}$ decreases and subsequently reaches values up to 6 units. The optimal shelf life for chilled meat should not exceed the value of the second zone. If to compare the $\mathrm{pH}$ value, its indicators for grass carp in the cooled state in the first zone had a range of $6-6,3$; in the second - 6,16: in the third - an increase in value up to 6,93 , which characterizes the staleness of the fish.

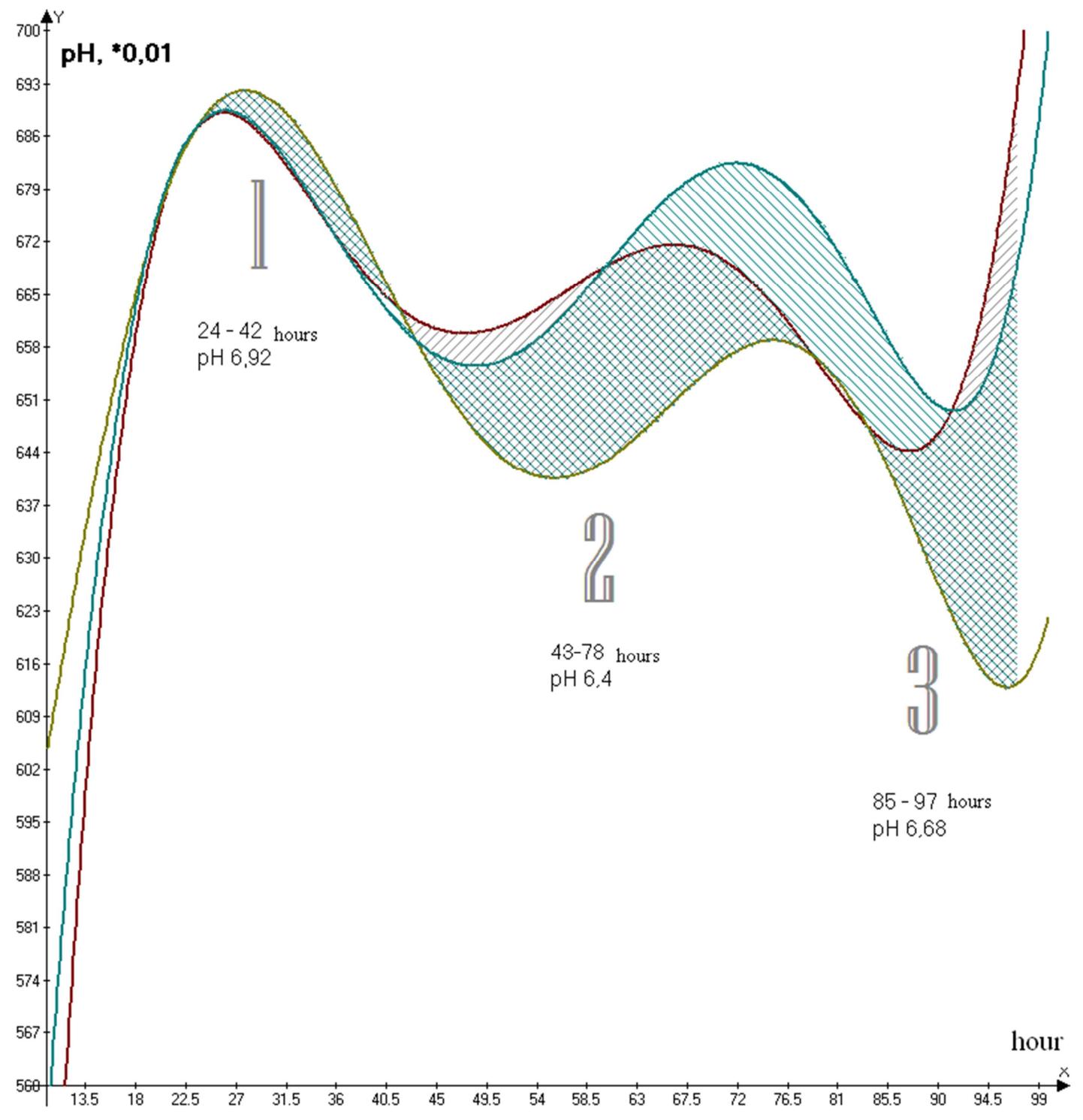

Figure 6. Dependence of $\mathrm{pH}$ on storage time at a temperature of $2-4^{\circ} \mathrm{C}$. 
During the long-term low-temperature storage, the $\mathrm{pH}$ value increases up to 7,58 , so it is recommended to store the spiny dogfish for no more than 3 months.

It should be noted that the shelf life as well as its temperature regime are important factors in the quality of the spiny dogfish meat. Prolonged storage causes the moisture loses and changes in density. After a day, the density in sample 2 is $985 \pm 34,4 \mathrm{~kg} / \mathrm{m}^{3}$ comparing to the initial value of $1028 \pm 37,3 \mathrm{~kg} / \mathrm{m}^{3}$. After freezing, the loss of moisture led to the equalization of density in the range of $1014,83 \pm 23,13$ $\mathrm{kg} / \mathrm{m}^{3}$. At the same time, with the decrease in the density and moisture of the sample, an increase in the tensile deformation force is recorded; it means that the coefficient of elasticity and, consequently, the stiffness of the spiny dogfish meat, increases. Thus, the spiny dogfish meat, like any other, undergoes various stages of autolytic changes, which changes not only $\mathrm{pH}$ values and meat density, but also the structural and mechanical properties and thermophysical characteristics of raw materials.

Comparative characteristics of the tensile deformation for the spiny dogfish depending on the shelf life is shown in table 1.

Table 1. Comparative characteristics of tensile deformation for the spiny dogfish depending on the shelf life.

\begin{tabular}{|c|c|c|c|c|c|c|c|}
\hline \multirow{2}{*}{ Part of the carcass } & \multirow{2}{*}{ Cutting direction } & \multicolumn{2}{|c|}{ Sample 1} & \multicolumn{2}{|c|}{ Sample 2} & \multicolumn{2}{|c|}{ Sample 3} \\
\hline & & $\mathbf{F}_{\text {def }}, \mathbf{N}$ & $t_{\text {def }}, s$ & $\mathbf{F}_{\text {def }}, \mathbf{N}$ & $t_{\text {def, }}, s$ & $\mathbf{F}_{\text {def }}, \mathbf{N}$ & $\mathbf{t}_{\text {def }}, \mathbf{s}$ \\
\hline \multirow{3}{*}{ Near the head } & Along & $4,9 \pm 0,23$ & $2,1 \pm 0,10$ & $3,9 \pm 0,19$ & $2,6 \pm 0,13$ & $1,18 \pm 0,05$ & $3,2 \pm 0,15$ \\
\hline & Across & $3,5 \pm 0,17$ & $3,1 \pm 1,15$ & $1,6 \pm 0,07$ & $6,5 \pm 0,31$ & $1,1 \pm 0,05$ & $2,8 \pm 0,13$ \\
\hline & Diagonally & $3,3 \pm 0,16$ & $2,9 \pm 0,14$ & $3,4 \pm 0,17$ & $2,8 \pm 0,14$ & $2,15 \pm 0,10$ & $1,8 \pm 0,08$ \\
\hline \multirow[b]{2}{*}{ Middle part } & Along & $4,1 \pm 0,20$ & $2,6 \pm 0,13$ & $3,7 \pm 0,15$ & $2,6 \pm 0,12$ & $1,8 \pm 0,08$ & $2,1 \pm 0,10$ \\
\hline & Across & $3,8 \pm 0,19$ & $2,7 \pm 0,13$ & $3,0 \pm 0,14$ & $2,8 \pm 0,13$ & $1,15 \pm 0,05$ & $3,1 \pm 0,15$ \\
\hline \multirow{3}{*}{ At the tail } & Along & $3,7 \pm 0,18$ & $2,9 \pm 0,14$ & $3,1 \pm 0,15$ & $3,1 \pm 0,15$ & $1,5 \pm 0,07$ & $2,5 \pm 0,12$ \\
\hline & Across & $4,5 \pm 0,22$ & $2,3 \pm 0,11$ & $2,8 \pm 0,13$ & $3,9 \pm 0,19$ & $1,1 \pm 0,05$ & $2,6 \pm 0,12$ \\
\hline & Diagonally & $3,0 \pm 0,14$ & $3,6 \pm 0,17$ & $2,6 \pm 0,12$ & $3,3 \pm 0,16$ & $1,1 \pm 0,05$ & $3,1 \pm 0,15$ \\
\hline
\end{tabular}

Values are means \pm SD of triplicate determination. Means in the same row with different superscript are significantly $(\mathrm{p}<0,05)$ different.

Therefore, the highest value of deforming force was observed in sample 1 - from $44,1 \div 3,7 \mathrm{~N}$, for sample 2 this indicator decreased by $9,7-16,7 \%$ from the initial values and was $3,7 \div 3,1 \mathrm{~N}$, and for sample 3 this indicator decreased by $56,1-59,4 \%$ and was $1,8 \div 1,5 \mathrm{~N}$; which indicates a decrease in the elastic properties of the object under prolonged low temperature storage. Ice crystals break the collagen fibers of the fish muscles and the sample becomes more plastic.

Rheological properties of fresh samples of mature spiny dogfish have been studied (Table 2) in comparison with the values of young individuals. The absolute elongation of all samples was $2 \mathrm{~cm}$, which was $28,6 \%$ of elongation from the initial length of the sample.

Table 2. Rheological properties of the spiny dogfish.

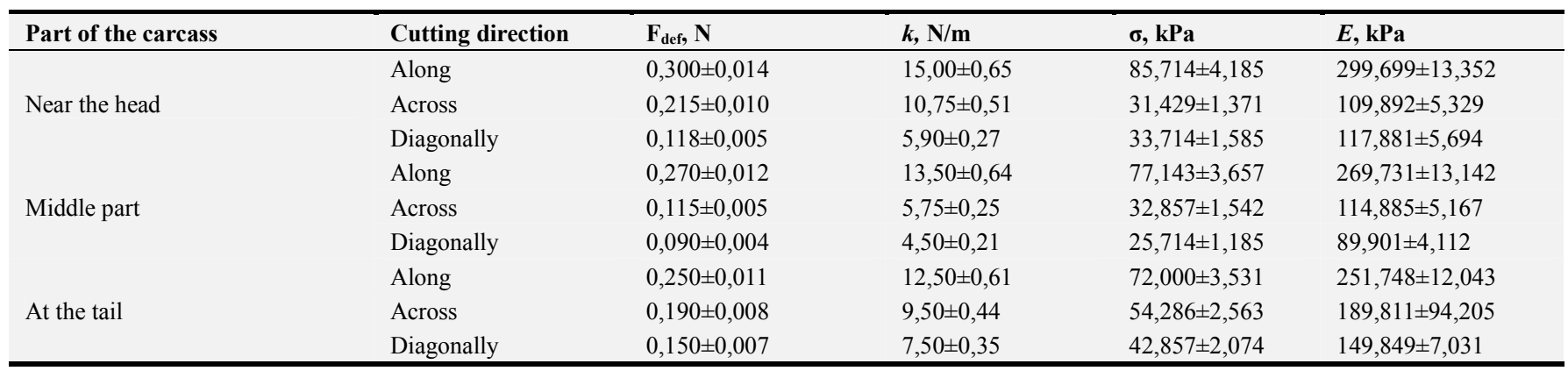

Values are means \pm SD of triplicate determination. Means in the same row with different superscript are significantly ( $<<0,05$ ) different.

It should be noted that the samples were fresh, did not undergo thermal treatment of both, high and low temperatures. The largest coefficients of modulus of elasticity belong to the samples having a diagonal cut. The coefficient of elasticity for these samples averages within 13,6 N/m. Compared with young individuals, mature ones have more elastic meat and higher values of strain coefficients. For young spiny dogfish individuals, the coefficient of elasticity of the samples taken near the head averaged $8,21 \mathrm{~N} / \mathrm{m}$, for the middle part samples $-6,18 \mathrm{~N} / \mathrm{m}$, and for the tail carcass part $-7,62 \mathrm{~N} / \mathrm{m}$.
The regression equation of the dependence of the deformation force on the absolute elongation has a fairly high approximation coefficient - 0,9932. For a more accurate analysis, it is necessary to divide the graph into linear dependences, and then from the obtained regression equations we obtain the numerical value of the coefficient of elasticity of the sample. Thus, the coefficient of elasticity is $165,49 \mathrm{~N} / \mathrm{m}$ when a fresh sample of the diagonal cut near the head of the spiny dogfish is deformed by $3,7 \%$. With further deformation of the sample up to $15 \%$, the coefficient of elasticity is 
stabilized within $81,28 \mathrm{~N} / \mathrm{m}$; when the deformation is extended up to $30 \%$, the coefficient of elasticity increases sharply and is within $226,2 \mathrm{~N} / \mathrm{m}$. At the further deformation the sample breaks.

Results of physical properties are placed in the process of

$$
\mathrm{Y}_{1}=35,25-5,36 \mathrm{x}_{1}+2,865 \mathrm{x}_{2}-3,75 \mathrm{x}_{3}+3,86 \mathrm{x}_{1} \mathrm{x}_{2}+0,355 \mathrm{x}_{2} \mathrm{x}_{3}+2,35 \mathrm{x}_{1}{ }^{2}-0,682 \mathrm{x}_{2}{ }^{2}-6,0568 \mathrm{x}_{3}{ }^{2}
$$

Mathematical model for storage temperature indicators:

$$
-Y_{2}=88,78+8,06 x_{1}-9,105 x_{2}+12,41 x_{3}-16,34 x_{1} x_{2}-8,99 x_{2} x_{3}+19,09 x_{1}{ }^{2}+9,92 x_{2}{ }^{2}+18,096 x_{3}^{2}
$$

Mathematical model for mass loss indicators:

$$
\mathrm{Y}_{3}=-0,37-2,14 \mathrm{x}_{1}+0,48 \mathrm{x}_{2}+3,02 \mathrm{x}_{3}-8,25 \mathrm{x}_{1} \mathrm{x}_{2}+12,01 \mathrm{x}_{2} \mathrm{x}_{3}-12,17 \mathrm{x}_{1}{ }^{2}+3,86 \mathrm{x}_{2}{ }^{2}-4,26 \mathrm{x}_{3}{ }^{2}
$$

where: $\mathrm{Y}_{1}-$ shelf life, days;

$\mathrm{Y}_{2}$ - storage temperature, ${ }^{\circ} \mathrm{C}$;

$\mathrm{Y}_{3}$ - storage temperature, ${ }^{\circ} \mathrm{C}$;

$\mathrm{x}_{1}-\mathrm{pH}$ of the sample;

$\mathrm{x}_{2}-$ strength of the sample (penetration value), $\mathrm{kPa}$;

$\mathrm{x}_{3}$ - content of nitrogenous extractives, $\%$.

According to the developed models it is possible to determine the optimal compromise areas of the spiny dogfish storage: at a temperature of $-15 \ldots-20^{\circ} \mathrm{C}-$ for $25 . .45$ days, at a temperature of $-25 \ldots-27^{\circ} \mathrm{C}-$ for $70 . .83$ days. The longest shelf life of chilled spiny dogfish is possible at a temperature of $+2^{\circ} \mathrm{C}$ for up to 48 hours, at a temperature of $+4^{\circ} \mathrm{C}$ the shelf life is reduced to 36 hours.

It is important to forecast changes in the quality of food products in order to establish the duration of storage, ensure a guaranteed level of quality during the movement of goods and sales in the retail network.

Only the general indicators of the consumer value of the spiny dogfish are known, without taking into account the mass-size characteristics and age features, which do not provide complete information about its nutritional value and usability. There is a need for additional studies of the chemical and mineral composition of the Black Sea spiny dogfish by age groups that differ in the degree of assimilation of toxic metals, as evidenced by previous studies.

One of the main tasks is to saturate the domestic market with quality biologically valuable food products based on comprehensive processing of the Black Sea dogfish with a guaranteed level of safety.

\section{Conclusion}

Studies on structure of the muscle tissue histological sections of the spiny dogfish is an important indicator of the freshness of the fish. These studies have shown the dimensional characteristics of the spiny dogfish muscle fibers, fat capsules and skin.

Functional dependence of the elastic coefficient on the value of the relative elongation of the sample has been established. The coefficient of elasticity is characterized by the highest value for the samples taken near the head and tail parts of the carcass, and the lowest - for the middle part. Studies of structural and mechanical parameters and microstructure of tissues play an important role in the process of forecasting the shelf life of fish and establishing temperature regimes in order to preserve the quality characteristics of fish raw materials.

\section{References}

[1] FAO. Aquaculture (2020) [Online]. Available at: $\mathrm{http}: / / \mathrm{www}$.fao.org/state-of-fisheries-aquaculture. [Accessed: 16.09.2020].

[2] Bolila N. O. (2016) The influence of morphometric characteristics on consumer properties of the black sea dogfish. Bulletin of the Lviv Commercial Academy. Series Commodity Studies 16. C. 119-122.

[3] Sydorenko O., Bolila N., Donchevska R. (2018) Consumer properties of a spiny dogfish (Squalus acanthias). Commodities and markets 3 (27), 57-65.

[4] Sydorenko O., Bolila N., Belinska S. (2020) The mineral composition of the Black Sea dogfish (Squalus acanthias). Commodities and markets 1 (33), 47-56.

[5] Jun-Hu Cheng, Da-Wen Sun (2014) Hyperspectral imaging as an effective tool for quality analysis and control of fish and other seafoods: Current research and potential applications. Trends in Food Science \& Technology 37, 78-91.

[6] Pan T-T, Sun D-W, Cheng J-H, Pu H. (2016) Regression algorithms inhyperspectral data analysis for meat quality detection andevaluation. Comprehen Rev Food Sci Food Saf 15, 529-541.

[7] Cheng, J. H., Sun, D. W., Han, Z. \& Zeng, X. A. (2014). Texture and structure measurements and analyses for evaluation of fish and fillet freshness quality: a review. Comprehensive Reviews in Food Science and Food Safety 13, 52-61.

[8] Abdo Hassoun, Romdhane Karoui (2017) Quality evaluation of fish and other seafood by traditional and nondestructive instrumental methods: Advantages and limitations. Crit Rev Food Sci Nutr 57 (9), 1976-1998.

[9] FAA Barraza, RAQ León, PXL Álvarez.(2015) Kinetics of protein and textural changes in Atlantic salmon under frozen storage. Food Chemistry 182, 120-127.

[10] Shapoval, S., Romanenko, R. P., Forostyana, N. P. (2017) Diagnosis of physical properties of food: Monograph. Kiev: KNUTE. 
[11] Shapoval, S. (2017) Improved method to determine structural-mechanical properties of turkey meat at axial deformation. Eastern-European Journal of Enterprise Technologies 1 (10), 63-69.

[12] Sydorenko, O., Bolila, N., Forostyana, N. (2016) Forecasting of structural characteristics of the black sea dogfish depending on a deformation force impulse. Bulletin of NTU "KhPI". Series: New solutions in modern technologies. - Kharkiv: NTU "KhPI" 42 (1214), 205-210.
[13] Guc' V. S., Sydorenko O. V., Romanenko O. V. (2006) Structural-mechanical properties of fish-breeding products. Commodities and markets 2, 127-134.

[14] Romanenko O., Sydorenko O., Shapoval S. (2019) Structural-mechanical properties of fish preserves during storage. Commodities and markets 1, 71-83.

[15] Gorbatov A. V., Maslov A. M., Machihin Ju. A. (1982) Structural and mechanical characteristics of food products. Moskow: Legkaja i pishhevaja promyshlennost. 